\title{
Impacts of Herbicide Exposure on Seminal Parameters among Oil Palm Plantation Workers in Lampung Province, Indonesia
}

\author{
Sutyarso $^{1}$, M. Kanedi ${ }^{2, *}$ \\ ${ }^{1}$ Department of Biomedical Sciences, Faculty of Medicine, University of Lampung, Indonesia \\ ${ }^{2}$ Department of Biology, Faculty of Mathematics and Sciences, University of Lampung, Indonesia \\ *Corresponding author: wegayendi@yahoo.com
}

Received December 08, 2014; Revised December 26, 2014; Accepted December 30, 2014

\begin{abstract}
It is a cross-sectional study to evaluate semen quality of plantation workers that due their daily obligation make them susceptible to herbicide exposures. The research participants were male workers of oil palm plantations in the District of Lampung Tengah, Lampung Province, Indonesia. They were those who meet the criteria of having more than one year work experience with herbicide, married and having children. Semen samples were taken by asking the participants to masturbate after they were advised to abstain from sexual intercourse for 4-5 days. Semen quality parameters that examined are volume, $\mathrm{pH}$, sperm count, sperm motility, normal morphology and HOS-test. Based on years of the work periods, there were three groups of participants obtained. Group-1 are the participants who worked less than 10 years; group- 2 are those who have work periods of 10-20 years; while group-3 are those who have worked more than 20 years. All of the semen quality parameters, except $\mathrm{pH}$, decreased significantly with the increase in work periods far beyond the maximum decrease in normal elderly male. In conclusion, the daily tasks of oil palm plantation workers which prompt them expose to herbicide, suspected to be the cause of the decrease in semen quality parameters.
\end{abstract}

Keywords: pesticide, herbicide, semen parameters, plantation workers

Cite This Article: Sutyarso, and M. Kanedi, "Impacts of Herbicide Exposure on Seminal Parameters among Oil Palm Plantation Workers in Lampung Province, Indonesia." American Journal of Biomedical Research, vol. 2, no. 4 (2014): 83-87. doi: 10.12691/ajbr-2-4-5.

\section{Introduction}

In the last two decades, oil palm plantations have been expanded intensively in Indonesia. [1] One of the provinces in Indonesia where oil palm was cultivated massively is Lampung Province. [2] Nowadays thousands of people in Lampung, a province located in the most southern part of Sumatra, relied on the oil palm cultivation as a livelihood. Thus, there would be thousands of people involved in the plantations management including in handling agrochemicals such as pesticides.

Pesticides that are commonly used in the oil palm cultivation management are herbicide - a typical pesticide for fighting weeds. [3] There were hundreds of herbicide brands marketed in Indonesia that comprises of the following chemicals: paraquat (class Ib), 2,4-D dimethylamine (class II), triclopyr butoxyethyl (class-II), glyphosate (class III), glufosinate-ammonium (class III) and metsulfuron-methyl (class IV). The classes of herbicide Ib, II, III and IV respectively mean: highly hazardous, moderately hazardous, slightly hazardous and unlikely to present acute hazard in normal use [4].

Ironically, in Lampung, the herbicides of most commonly used to eradicate weeds in oil palm plantations were of class II and III. The health impacts of such herbicides exposure have been revealed in many laboratory and epidemiological reports.

As summarized by Karr et al. (2007), herbicides are hazardous not only for its acute toxicity but also for chronic effects. [5] Glyhosate, for example, causing many chronic pathological effects in rats including the incident of mammary tumors and palpable tumors, liver congestions and necrosis, kidney nephropathies and sex hormones imbalance [6].

In human subjects the chronic impacts of herbicides have also been widely studied. Tuc et al. (2007) reported that in Vietnam male farmers without personal protective equipments when handling the pesticides were being at risk of abnormal semen. [7] The risk of a man exposed to herbicides to have abnormal semen parameters is 3 to 9 times greater compared to those who did not [8].

As is the case in Vietnam, most plantation workers in Indonesia, especially in Lampung tend to neglect safety procedures in handling agrochemicals. This carelessness can be caused by several conditions, among others, due to low education and lack of socialization about the latent dangers of pesticides. As the consequence, they have become accustomed to not wearing any personal protective equipment. Such habits, of course, make them vulnerable to health problems [9]. 
Unfortunately, in Indonesia, scientific studies on the impact of herbicide exposure on the reproductive health of farmers and plantation workers are rarely done. This study, thereby, conducted to investigate the relationship between semen parameters of the oil palm plantations workers with the work period that they spent.

\section{Materials and Methods}

\subsection{The Date and Area of Study}

This study was conducted in April to July 2013 in the district of Lampung Tengah, the province of Lampung, Indonesia.

\subsection{The Participants and Ethical Clearance}

The research participants were male workers of oil palm plantations who involved in plantation management such as planting, pruning, thinning, harvesting, replanting and clearing weeds, including mixing, loading and applying the herbicide. The targeted workers were those who meet the criteria of married, having children and had more than one-year of work experience.

Ethical clearance for the study was obtained from the Ethics Committee of the Faculty of Medicine, University of Lampung, Indonesia. For ethical reason, before being involved in the study, all of the participants have voluntarily wrote consent to participate. The procedures, the benefits, and the risks of the study were clearly stated. They were also told that all information relating to the biological samples and data in this study will be kept confidential.

\subsection{Seminal Fluid Sampling and Analysis}

Semen sample was taken from the participants by asking them to masturbate. Prior to do masturbation, all participants were advised to abstain from sexual intercourse for 4-5 days. Semen samples collected in a wide-mouthed-sterile glass container. Information about the date and time of ejaculation recorded on each semen container. All semen samples were kept in room temperature until liquefaction and examination using guidelines from the WHO [10].

Seminal fluid volume and $\mathrm{pH}$, sperm concentration, motility, and morphology examined and recorded as semen quality parameters. Seminal volume was determined using graduated pipette with an accuracy of $0.1 \mathrm{ml}$. The sperm motility as well as sperm concentration was examined with haemocytometer using a light microscope with a magnification of 400x. To assess the sperm morphology, the Giemsa-stained slides prepared and then examined using light microscope at a magnification of 1000x.

To confirm the effects of herbicide exposure on sperm membrane integrity, the hypoosmotic swelling test (HOStest), adopted from Hossain et al. (1998), was performed. To perform the test, $100 \mu$ l of semen sample mixed with $900 \mu \mathrm{l}$ of $60 \mathrm{mOsm}$ sodium citrate and fructose. After incubated for 30 minutes at $37^{\circ} \mathrm{C}, 10 \mu \mathrm{l}$ of the samples was smeared on a microscopic slide. Total of 100 sperm cells then chosen randomly and observed using a light microscope. Based on the presence or absence of coiled and swelling tails in the sperm cells, the spermatozoa were classified into positive or negative [11].

\subsection{Statistical Analysis}

To compare the semen parameters among the worker groups, one-way ANOVA and LSD post hoc test were used. The strength of the relationship between variables was analyzed using Pearson Correlation test. Both of the statistics that applied are programmed in SPSS version 18.

\section{Results}

\subsection{Characteristic of the Participants}

Of a total of 102 plantation workers to whom we send informed consent form, 88 had been participated in this survey. Their ages were range from 25 up to 82 years (mean=47.19) with the work period range from 4 up to 35 years (mean=16.66). Of the 88 participants, $44(50 \%)$ are smoking, 30 (34.1\%) are not smoking, 14 (15.9\%) quit smoking and none of them drinking alcohol. Based on the participant work periods they were grouped into three. Group-1 (G1) is the participants who worked less than 10 years $(n=28)$; group-2 (G2) is those who have working periods of $10-20$ years $(n=28)$; while group-3 (G3) is those who have worked more than 20 years $(n=32)$. The descriptive statistics of age, body mass index (BMI) and years of work period of each worker group are presented in Table 1.

Table 1. The age, BMI, and work period of the participants

\begin{tabular}{|c|c|c|c|c|c|c|}
\hline Variables & Groups & $\mathbf{N}$ & Mean & SD & Min & Max \\
\hline \multirow{3}{*}{ Age (years) } & G1 & 28 & 31.07 & 4.15 & 25 & 40 \\
\hline & $\mathrm{G} 2$ & 28 & 46.86 & 12.39 & 25 & 72 \\
\hline & Total & 88 & 47.19 & 15.55 & 25 & 82 \\
\hline \multirow{4}{*}{ BMI (kg/m2) } & G1 & 28 & 20.68 & 2.07 & 17.51 & 25.39 \\
\hline & $\mathrm{G} 2$ & 28 & 21.25 & 2.08 & 17.63 & 25.39 \\
\hline & G3 & 32 & 21.66 & 1.54 & 18.14 & 24.22 \\
\hline & Total & 88 & 21.22 & 1.92 & 17.51 & 25.39 \\
\hline \multirow{4}{*}{ Work period (years) } & G1 & 28 & 6.57 & 1.71 & 4 & 8 \\
\hline & G2 & 28 & 14.93 & 16.18 & 10 & 20 \\
\hline & G3 & 32 & 27.00 & 28.42 & 21 & 35 \\
\hline & Total & 88 & 16.66 & 9.09 & 4 & 35 \\
\hline
\end{tabular}




\subsection{Semen Quality}

Mean values and one-way ANOVA of the semen quality parameters among participant groups are summarized in Table 2, while the post hoc LSD-test of it is presented in
Table 3. In Table 3 it is clear that among the six parameters of semen quality, only $\mathrm{pH}$ that did not show any significant different between groups. While the other fives are differ very significantly with the difference in work period.

Table 2. Mean value and ANOVA of semen quality parameters among participants

\begin{tabular}{|c|c|c|c|c|}
\hline \multirow{2}{*}{ Variables } & G1 & $\mathrm{G} 2$ & G3 & ANOVA \\
\hline & $($ mean $\pm \mathrm{SD})$ & $($ mean \pm SD $)$ & $($ mean $\pm \mathrm{SD})$ & $F$ \\
\hline Semen volume (ml) & $3.39 \pm 0.39$ & $2.71 \pm 0.50$ & $2.50 \pm 0.45$ & 32.094 \\
\hline $\mathrm{pH}$ of semen & $7.23 \pm 0.17$ & $7.22 \pm 0.25$ & $7.29 \pm 0.31$ & 0.807 \\
\hline Sperm concentration $\left(10^{6} / \mathrm{ml}\right)$ & $68.04 \pm 15.79$ & $41.32 \pm 21.47$ & $27.91 \pm 12.09$ & 44.061 \\
\hline Sperm motility (\%) & $79.93 \pm 9.59$ & $56.78 \pm 15.12$ & $46.53 \pm 7.95$ & 66.889 \\
\hline Normal morphology (\%) & $76.71 \pm 5.24$ & $62.21 \pm 14.53$ & $50.34 \pm 9.75$ & 47.030 \\
\hline HOS-test (\%) & $73.00 \pm 6.54$ & $55.36 \pm 14.34$ & $47.78 \pm 8.59$ & 46.455 \\
\hline
\end{tabular}

G1=working period < 10 years; G2=working period 10-20 year; G3=working period > 20 years

Table 3. Post hoc LSD-test of semen quality parameters between groups

\begin{tabular}{lccc}
\hline \multirow{2}{*}{ Variables } & \multicolumn{3}{c}{ Difference of mean } \\
\cline { 2 - 4 } & $\mathrm{G} 1-\mathrm{G} 2$ & $\mathrm{G} 1-\mathrm{G} 3$ & $\mathrm{G} 2-\mathrm{G} 3$ \\
\hline Semen volume $(\mathrm{ml})$ & $.682^{* * *}$ & $.899^{* * *}$ & .217 \\
$\mathrm{pH}$ of semen & .011 & .065 & .076 \\
Sperm concentration $\left(10^{6} / \mathrm{ml}\right)$ & $26.714^{* * *}$ & $40.129^{* * *}$ & $13.415^{* *}$ \\
Sperm motility $(\%)$ & $23.143^{* * *}$ & $33.397^{* * *}$ & $10.254^{* * *}$ \\
Sperm morphology $(\%)$ & $14.500^{* * *}$ & $26.371^{* * *}$ & $11.871^{* * *}$ \\
HOS-test $(\%)$ & $17.643^{* * *}$ & $25.219^{* * *}$ & $7.576^{* *}$ \\
\hline Statistical significance: $* P<0.05 ; * * P<0.01, * * * P<0.001$. &
\end{tabular}

\subsection{Relationship between the Working Period} and the Semen Parameters

The data in Table 2 and Table 3 clearly indicates that the semen quality parameters of male workers affected by the duration of work period. When all the semen quality parameters correlated with the work period using Pearson correlation test then we obtain the correlation coefficient (r) as listed in Table 4. In accordance with the results of ANOVA and its post hoc test, here, only the $\mathrm{pH}$ that did not show any correlation with the work period. However, the other five parameters i.e. semen volume, sperm concentration, motility, morphology, and HOS-test are correlated strongly and negatively with the work period $(\mathrm{p}<0.01)$.

Table 4. Correlation coefficient $(r)$ of the relationship between the mean value of working period and the semen parameters

\begin{tabular}{clcc}
$\begin{array}{c}\text { Independent } \\
\text { variables }\end{array}$ & Dependent variables & $\boldsymbol{r}$ & $\boldsymbol{P}$ \\
\hline \multirow{5}{*}{ Work period (years) } & Semen volume (ml) & -.574 & .000 \\
& pH of semen & .136 & 0.207 \\
& Sperm concentration $\left(10^{6} / \mathrm{ml}\right)$ & -.635 & .000 \\
& Sperm motility $(\%)$ & -.708 & .000 \\
& Sperm morphology $(\%)$ & -.662 & .000 \\
& HOS-test (\%) & -.629 & .000 \\
\hline
\end{tabular}

\section{Discussion}

As shown in Table 4, there is a strong negative correlation between the parameters of semen quality with the work period spent by the oil palm plantation workers. Of course, this fact does not necessarily indicate a causal relationship between the two. Two other variables, namely BMI and age of participants may also affect the quality of the semen of the participants.

Regarding BMI, current finding showed that in average the BMI of the participants is 21.22. Refer to the appropriate body-mass index for Asian populations issued by WHO Expert Consultation, BMI of the current study participants fall within the normal range (acceptable). [12] Thus, the effect of BMI on the semen quality of the participants can be ignored. Mac Donald et al. (2013) found that even in obese men there was no significant correlation between BMI and the semen parameters as well as the relative risk of abnormal semen [13].

While the relationship between participants' semen qualities with their BMI can be ignored, not the case with age. Molina et al. (2010), based on a retrospective study of 9168 cases in men aged between 20-77 years, found that in relation to age, seminal volume, sperm count, motility, viability and normal morphology showed a significant decrease [14].

Our results show a similar thing with it. As can be interpreted from Table 2 and Table 3, except for $\mathrm{pH}$, all semen quality parameters significantly reduced in the elderly. However, to ascertain whether the decline in semen quality among the participants of this study is related to age or period of work, the following data should be considered. In a review article, Kidd et al. (2001) summarizes that when comparing the 50-year-old men with the 30-year-old men, the maximum decrease in semen volume was $22 \%$, maximum decrease in sperm motility was $37 \%$, and decrease in percent normal sperm was 18\%. [15] Our data for these parameters consecutively are $26.25 \%, 41.7 \%$, and $34.5 \%$ for the comparison between the 31-year-old participants with the 61-year-old ones.

Because the decline in semen quality parameters of current study participants exceeded the maximum decrease in normal elderly men, as indicated by Kidd et al., then there must be other factors to consider, one of which was the working period. Current results showed that the longer the work period spent by palm oil plantation workers the lower the scores of their semen volume, sperm count, motility, morphology, and percentage of normal sperm. These facts, make us believe that the low value of semen quality parameters among oil palm plantation workers in the province of Lampung very likely due to herbicide exposure. 
Pesticides, as reported by many researchers, can accumulate in living organism tissues as the duration of exposure. In fishes, pesticide residues accumulated in liver, gills, stomach, and flesh. [16] In frogs, pesticide residues were found in the whole body tissue [17].

In animals and humans, the herbicide residues have been reported to cause chronic effects on various organ systems and functions. In rats, glyphosate herbicides interferes with blood components including alteration of their basic composition, increase in red blood cell count and decrease in the $\mathrm{Hb} \%$. [18] On human subjects, the incidence of chronic respiratory diseases are increasing with the increasing of frequency and duration of pesticide exposure [19].

There are many epidemiological studies are confirmed by our findings, among others, a study conducted by Jerewich et al. (2010) which revealed that male subjects exposed to pesticide tend to have low sperm concentration and motility. [20] From Malaysia, Hossain et al. (2010) reported that farmers exposed to pesticides have a greater risk of having low semen quality compared to those who did not [21].

Biological impact of pesticides on living organisms is not only revealed through epidemiological studies but also through various experiments in the laboratory. Some herbicides are known to have detrimental effects on laboratory animals. Paraquat herbicides of low doses, for instance, in male rats caused the sperm count decrease but the sperm abnormalities and mortality were increased. These facts encourage D'Souza et al. concluded that the herbicide-paraquat is genotoxic as well as cytotoxic in germ cells [22].

In addition to the effects mentioned above, some herbicides are also known to cause hormonal/endocrine disturbances. Perhaps the poor quality of the semen among workers involved in this research related to the hormonal effects of herbicides. Glyphosate herbicides, as reported by Gasnier et al. (2009), causing disruption in human cell endocrine, transcriptional activities on estrogen receptors and aromatase transcription activities. [23] In addition, male rats exposed to 2-4 D (2,4Dichlorophenoxyacetic) herbicides showed a significant decrease in the level of testosterone, FSH and LH [24].

\section{Conclusion}

Careless habits of oil palm plantation workers in the province of Lampung, Indonesia, in handling agrochemicals for years in their work period allegedly make them vulnerable to health problems including reproductive health disruption.

\section{Limitation and Future Study}

It is a fact that the semen quality parameters strongly negatively correlated with the length of working period spent by workers. However, the period of work was not the only single factor that can be attributed to changes in semen quality. Age of participants which ranged from 25 to 82 years is another factor of current study that may weaken the final conclusion. For that reason the future studies which are intended to evaluate the consequences of the work period on health parameters should involve only participants of the same age.

\section{References}

[1] USDA, Indonesia: Rising Global Demand Fuels Palm Oil Expansion. United States Department of Agriculture. 2010.

[2] UNEP, Oil palm plantations: threats and opportunities for tropical ecosystems. UNEP Global Environmental Alert Service (GEAS). 2011.

[3] Mohamad RB, Wibawa W, Mohayidin MG, Puteh AB, Juraimi AS, Awang Y and Lasim MBM. "Management of Mixed Weeds in Young Oil-palm Plantation with Selected Broad-Spectrum Herbicides," Pertanika J. Trop. Agric. Sci. 2010; 33 (2): 193-03.

[4] WHO, The WHO recommended classification of pesticides by hazard and guidelines to classification. 2005.

[5] Karr, C.J., Solomon, G.M. and Brock-Utne, A.C. "Health Effects of Common Home, Lawn, and Garden Pesticides," Pediatr Clin N Am 2007; 54: 63-80.

[6] Séralini GE, Clair E, Mesnage R, Gress S, Defarge N, Malatesta M, Hennequin D and de Vendômoiset JS. Long term toxicity of a Roundup herbicide and a Roundup-tolerant genetically modified maize. Food Chem Toxicol 2012.

[7] Tuc VP, Wangsuphachart V, Tasanapradit P, Fungladda W, van Trong P and Nhung NT. "Impacts of pesticide use on semen characteristics among rice farmers in Kienxuong district, Thaibinh Province, Vietnam," Southeast Asian J Trop Med Public Health 2007; 38:569-75.

[8] Hossain F, Ali O, D'Souza UJA and Naing DKS. "Effects of pestcide use on semen quality among farmers in rural area of Sabah, Malaysia," Journal of Occupational Health 2010; 52: 35360.

[9] Sekiyama M, Tanaka M, Gunawan B, Abdoellah O and Watanabe C, "Pesticide Usage and Its Association with Health Symptoms among Farmers in Rural Villages in West Java, Indonesia," Environmental Sciences 2007; 14(Supplement 2007): 023-33.

[10] WHO, The WHO Laboratory Manual for The Examination and Processing of human semen. 5th ed. WHO Press. Geneva, Switzeland. 2010.

[11] Hossain, A.M., Rizk, B., Barik, S., Huff, C. and Thorneycroft, I.H., "Time course of hypo-osmotic swellings of human spermatozoa: evidence of ordered transition between swelling subtypes." Human Reproduction 1998; 13(6): 1578-1583.

[12] WHO Expert Consultation, "Appropriate body-mass index for Asian populations and its implications for policy and intervention strategies," Lancet 2004; 363: 157-63.

[13] MacDonald AA, Stewart AW and Farquhar CM. "Body mass index in relation to semen quality and reproductive hormones in New Zealand men: a cross-sectional study in fertility clinics," Human Reproduction 2013; 0(0): 1-10.

[14] Molina RI, Martini AC, Tissera A, Olmedo J, Senestrari D, de Cuneo MF and Ruiz RD., "Semen Quality and Aging: Analysis of 9.168 Samples in Cordoba, Argentina," Arch. Esp. Urol 2010; 63 (3): 214-221.

[15] Kidd SA, Eskenazi B and Wyrobek AJ. "Effects of male age on semen quality and fertility: a review of the literature," Fertility and Sterility 2001; 75(2):237-48.

[16] Akan JC, Mohammed Z, Jafiya L and Audu SI., "Organophosphorus Pesticide Residues in Different Tissues of Fish Samples from Alau Dam, Borno State, Nigeria," World Journal of Fish and Marine Sciences 2013; 5(5): 519-26.

[17] Smalling KL, Fellers GM, Kleeman PM and Kuivila KM. "Accumulation of Pesticides in Pacific Chorus Frogs (Pseudacris regilla) from California's Sierra Nevada Mountains, USA," Environmental Toxicology and Chemistry 2013; 32(9): 2026-34.

[18] Deshmukh US, Iram F and Joshi MS. "Effect of Acute Exposure of Glyphosate Herbicide, on Wistar Rats with Reference to Haematology and Biochemical Analysis," The Bioscan 2013; 8(2) 381-3.

[19] Ye M, Beach J, Martin JW and Senthilselvan A. "Occupational Pesticide Exposures and Respiratory Health,” Int. J. Environ. Res. Public Health 2013; 10: 6442-71.

[20] Jurewicz, J, Hanke W, Radwan M and Bonde JP. "Environmental factors and semen quality," Int J Occup Env Health 2010; 22: 30529. 
[21] Hossain, F., Ali, O., D’Souza, U.J.A. and Naing, D.K.S., "Effects of pestcide use on semen quality among farmers in rural area of Sabah, Malaysia.," Journal of Occupational Health, 2010, 52: 353-360.

[22] D'Souza UJA, Narayana K, Zain A, Raju S, Nizam HM and Noriah O. "Dermal exposure to the herbicide paraquat results in genotoxic and cytotoxic damage to germ cells in the male rat," Folia Morphol 2006; 65(1): 6-10
[23] Gasnier, C., Dumont, C., Benachour, N., Clair, E., Chagnon, M.C and Seralini, G.E., "Glyphosate-based herbicides are toxic and endocrine disruptors in human cell lines," Toxicology 262 (2009): 184-191.

[24] Joshi SC, Tibrewal P, Sharma A and Sharma P. "Evaluation of toxic effect of 2,4-D (2,4-dichlorophenoxy acetic acid) on fertility and biohemical parameters of male reproductive system of albino rats," Int J Pharm Pharm Sci 2012; 4(3): 338-42. 